\title{
Beneficiation of South African chromite tailings using Magnetic Separation
}

\author{
Thabo Mokoena, Willie Nheta \\ University of Johannesburg \\ P.O.BOX 17011, Doornfontein 2028, Johannesburg, South Africa \\ thabo@reamokoena.co.za; wnheta@uj.ac.za
}

\begin{abstract}
There are proven and well established widely accepted techniques for concentration of chromite ores such as spiral concentration, jigs and shaking tables. However, these techniques become inefficient and complex when treating fine and ultrafine size particles (less than $75 \mu \mathrm{m}$ ) resulting in this size fraction lost to the tailings. As a result, a wet magnetic separation technology for recovery of ultra-fine chromite $\left(\mathrm{Cr}_{2} \mathrm{O}_{3}\right)$ from spirals tailings as a scavenger was investigated. The Middle Group Chromitite layer (MG) spiral tailings was characterized using XRF, XRD, SEM and screen sieves with the aim of determining the viability of using the wet high intensity magnetic separation technology. It was found that the material had a grind size of $39.20 \%$ passing $106 \mu \mathrm{m}$. The size fraction below $106 \mu \mathrm{m}$ showed the chrome content averaging 33\%. The grain size of between $1000 \mu \mathrm{m}$ and $106 \mu \mathrm{m}$ showed an average chromite content of $12.7 \%$. The XRD results revealed that the sample is Magnesiochromite along with the different gangue minerals such as Quartz, Enstatite ferroan, F-Iron diiron. The chemical analysis of the head sample showed the presence of calcium, Magnesium, Aluminium, Iron and silica.
\end{abstract}

Keywords: Ultra-fine chromite tailings, Magnetic separation, Characterization, Chromite

\section{Introduction}

Chromite recoveries is a major concern particularly in processing of finely disseminated ores due to its inherent complexities. The gravity separation process is the main beneficiation process used to recover chromite mineral. However, these conventional chromite processing techniques become inefficient and complex when treating fine and ultrafine size particles (less than $75 \mu \mathrm{m}$ ) leading to losses $[1,2]$. Apart from that, separation of chromite from other associated minerals is sometimes very difficult owing to the complexity of ore texture along with presence of near density minerals. In chrome ore beneficiation, specific gravity and size-based separations are the most convenient and cost-effective methods [3, 4]. Majority of chromite ore beneficiating companies are searching for an economic way of beneficiating of ultrafine chromite for enrichment whilst removing unwanted gangue minerals, maximizing the recovery and minimizing operational cost. South African yearly chromite production has been increasing at an average production of $1500000 \mathrm{t}$ in the past 5 years except in 2016 where there was a slight decrease of approximately $900000 t$ [5].

Conventional chromite processes achieve an average recovery of between 50 and $65 \%$, which result in a mass yield of between 37 and $45 \%$. The low recoveries is due to ultrafine material which gets carried into the tailings section due to the force exerted by process water more especially when operating at a dilute slurry. This typical recovery indicates that South African chromite production can be increased by a further 15 to $20 \%$ provided that there is a technology that can recover fine and ultrafine chromite effectively.

Magnetic separation is a technology or process that exploits the difference in magnetic properties between the ore minerals and is employed to separate valuable mineral from nonmagnetic gangues. All materials are affected in some way when placed in a magnetic field. During the magnetic separation process, materials are classified into paramagnetic and diamagnetic depending on whether or not the effect of magnetic field on them are strong or not respectively. The capacity of a magnetic separator to lift a particular mineral is dependent not only on the value of the field intensity, but also on the field gradient, which is the rate at which the field intensity increases towards the magnet surface [6]. Production of a high field gradient as well as high intensity is therefore an important aspect of separator design.

In this project, chromite tailings from Western Limb of the South African Bushveld Igneous Complex (BIC) was characterised with the objective of recovering fine and ultrafine chromite using wet magnetic separation process. 


\section{Materials and Methods}

Chromite tailings ore sample was obtained from a MG chromite processing plant in the Western Limb of the Bushveld Igneous Complex (BIC), South Africa. Characterisation studies were carried out to quantify the different mineral phases, their liberation and association with each other [7]. Chemical composition of different sizes of the feed sample was carried out by X-ray florescence analyser (XRF). The particle size distribution analysis of the ore sample was carried out using dry vibrating laboratory sieve shaker. Mineral phases of the tailings were obtained using X-Ray diffraction (XRD) with $\mathrm{Cu}$ K $\alpha$ radiation. Evaluation of minerals by Scanning Electron Microscopy (SEM) was conducted.

\section{Results and Discussion}

\subsection{Chemical composition}

The chemical composition of the chromite tailings sample is shown in Table 1. Table 1 shows that the sample had a chromite content of $20.03 \%$ with silica as the major gangue measured at $33.50 \%$. The iron oxide content assayed at $17.94 \%$. The chromite content corroborates the research that was conducted by [4] which indicated that there is sufficient amount of chromite in tailings streams measuring between 9-20\% $\mathrm{Cr}_{2} \mathrm{O}_{3}$.

Table 1: Chemical composition of the chromite samples

\begin{tabular}{|l|l|l|l|l|l|}
\hline. & $\mathrm{MgO}$ & $\mathrm{Al}_{2} \mathrm{O}_{3}$ & $\mathrm{SiO}_{2}$ & $\mathrm{Cr}_{2} \mathrm{O}_{3}$ & $\mathrm{FeO}$ \\
\hline $\mathrm{MG}$ & 16.02 & 7.6 & 33.5 & 20.03 & 17.94 \\
\hline
\end{tabular}

\subsection{Mineralogical composition}

XRD analysis was carried out for identifying different mineral phases and the XRD pattern of the sample is depicted in Figure 1. XRD pattern shows, that along with the chromite, different gangue minerals such as B-Quartz, C-Enstatite ferroan, Iron diiron, Aluminium and Iron magnesium silicate are present in the sample. The results confirm the outcome of the study that was conducted [2] which indicated that the natural chromite mineral has five major components such as $\mathrm{MgO}, \mathrm{FeO}, \mathrm{Cr}_{2} \mathrm{O}_{3}, \mathrm{Al}_{2} \mathrm{O}_{3}$ and $\mathrm{Fe}_{2} \mathrm{O}_{3}$. XRD further indicates that chromite is associated with magnesium.

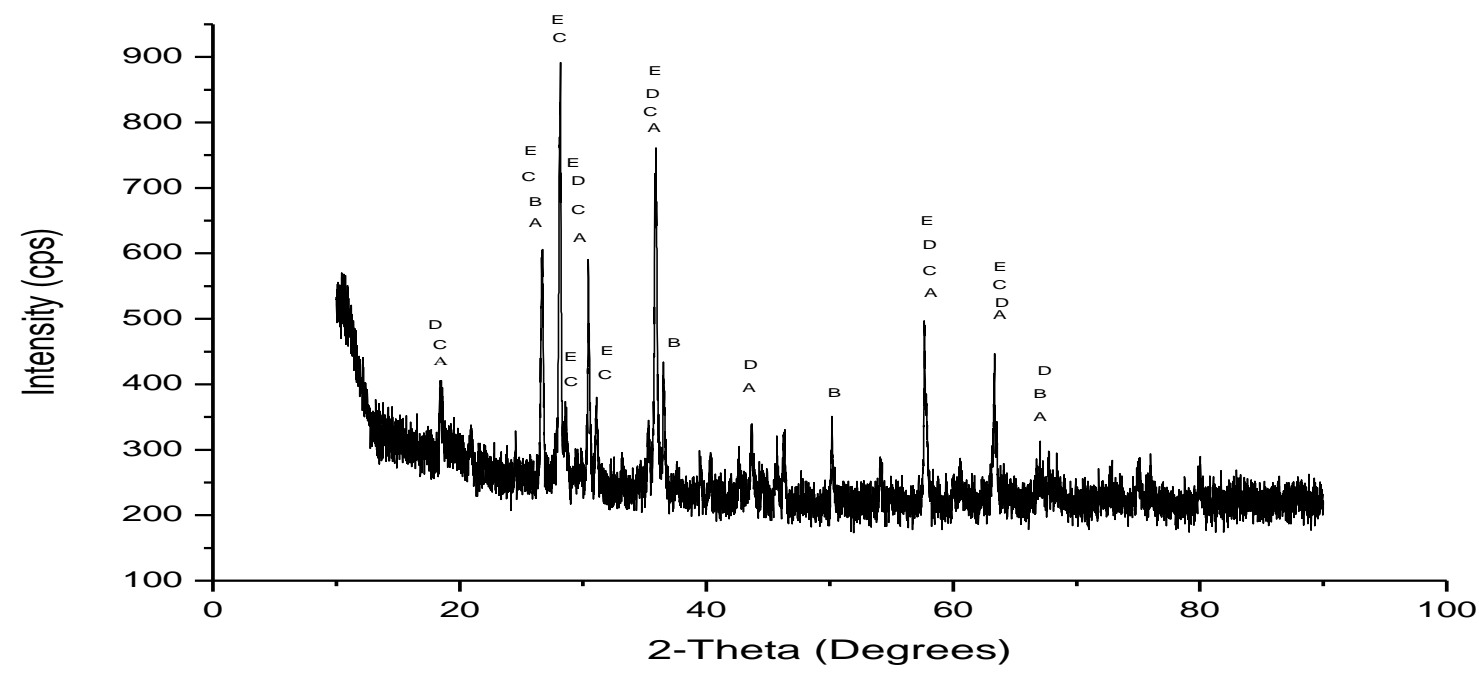

Fig.1: X-ray Diffraction for MG Chromite Sample

Where A - Magnesiochromite; B- Quartz; C - Enstatite Ferron; D - Aluminium and E - Iron Magnesium Catena Silicate 


\subsection{Particle Size Distribution}

Particle size distribution analysis was carried out on a dry screen shaker and the results are presented in Figure 2. The results indicate that the particle size distribution (PSD) of the sample is coarser which indicate a typical MG material spiral tails grind. The results further show a grind of $22 \%$ passing $75 \mu \mathrm{m}$. The coarser grind is a clear indication that the material consists of particles that are not fully liberated and others in which the mineral to be recovered is contained within composite particles, along with unwanted gangue mineral. The sample is $100 \%$ passing $1200 \mu \mathrm{m}$, whilst the $80 \%$ of the material passes $430 \mu \mathrm{m}$.

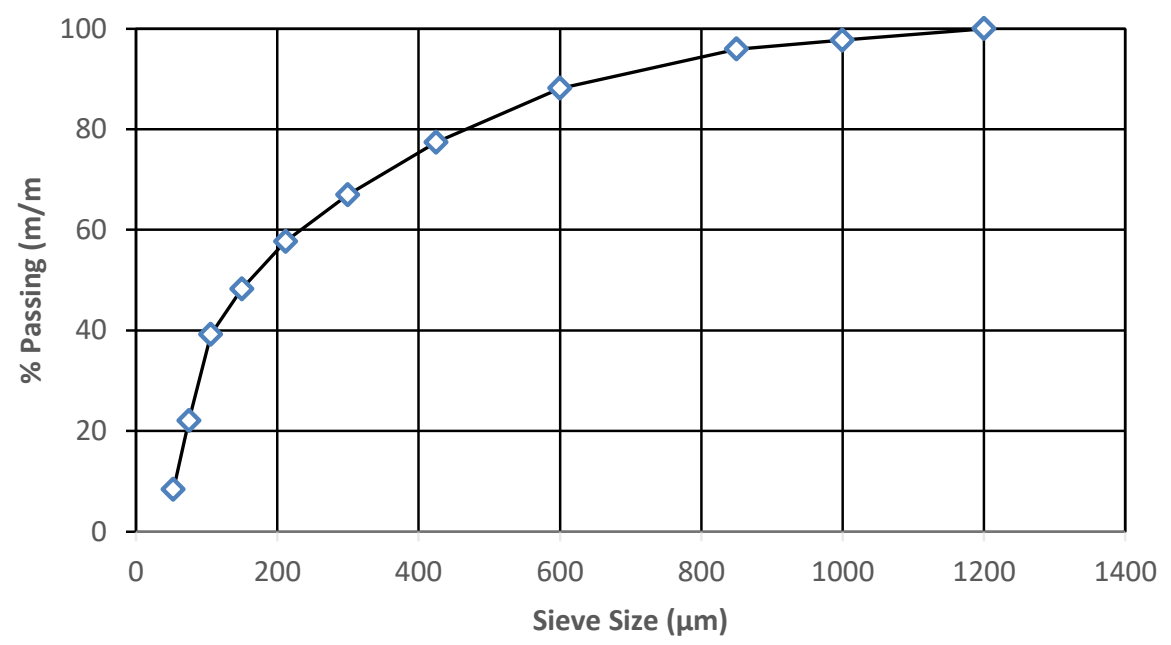

Fig. 2: Feed particle size distribution

\subsection{Chromite Deportation}

The feed sample was analysed for Chromite and Silica deportation and the results are shown Figure 3. Figure 3 shows that the highest chromite content averaging $33.58 \%$ is in the finer size fraction of below $75 \mu \mathrm{m}$. The fraction below $75 \mu \mathrm{m}$ indicates a $22.1 \%$ by mass of the material. This is a clear indication that the spiral technique was inefficient in recovering fine chromite which resulted in this size fraction getting lost to the tailings. Nonetheless, the results are highly favourable to magnetic separation, as the technology is dependent on the fineness of the material. As a result, it is expected that enriching of the chromite by magnetic separation will yield favourable results. The chromite content in the courser fraction is much lower at an average of $12.79 \%$. This is typical tailing which will be uneconomical to enrich. 


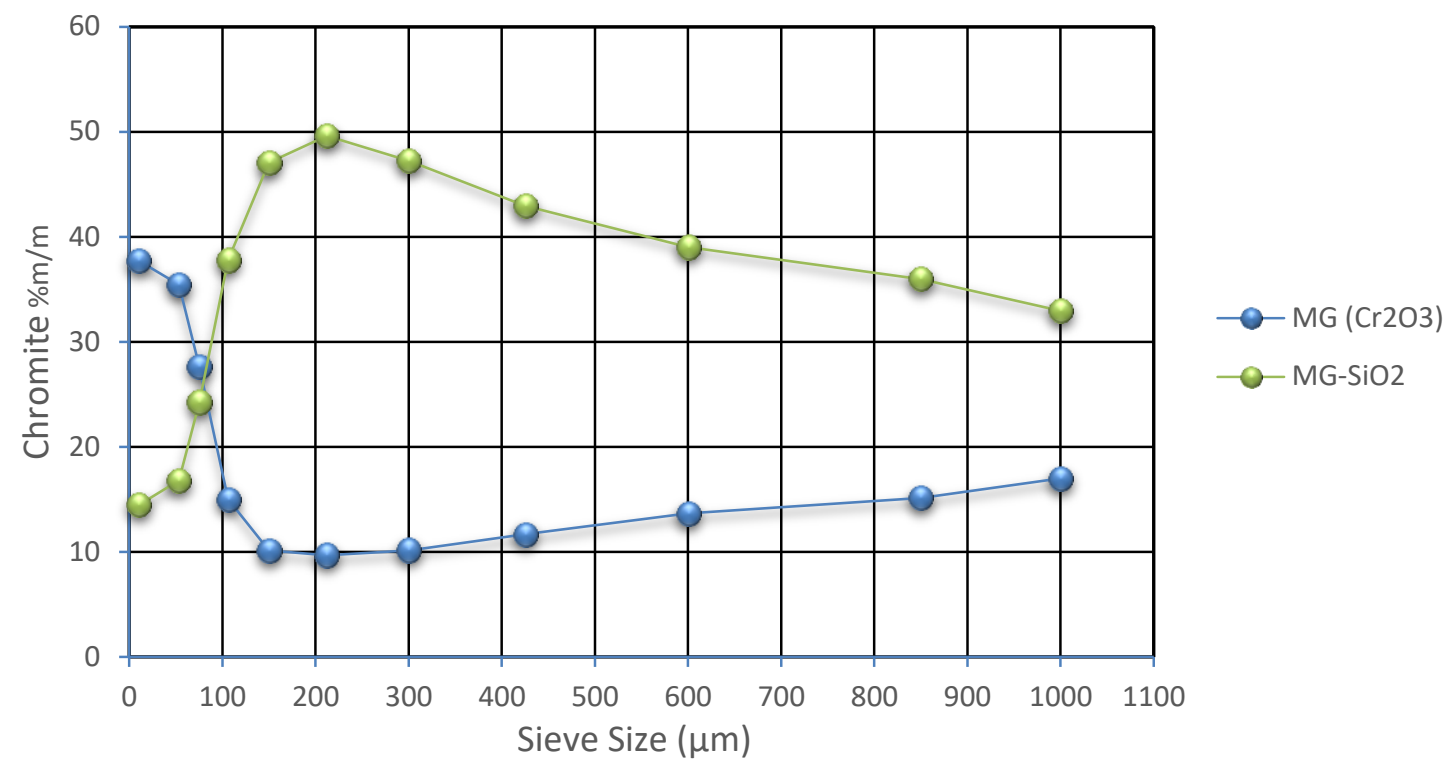

Figure 3: Chromite and Silica deportation

\subsection{SEM (Scanning Electron Microscopy)}

Scanning electron microscopy (SEM) study was carried out on the sample and the results are shown Figure 4. It is observed that sample is of low chromite grade and the chromite grains comprises loosely compacted crystals. SEM further shows that there are gangue minerals such Silica, Magnesium, Aluminium and iron. However, the main contributing gangue mineral is silica. The analysis of the different chromite grains as outlined by the 4 points on the micro-graph shows that the distribution of Magnesium is uniform throughout chromite spinel.

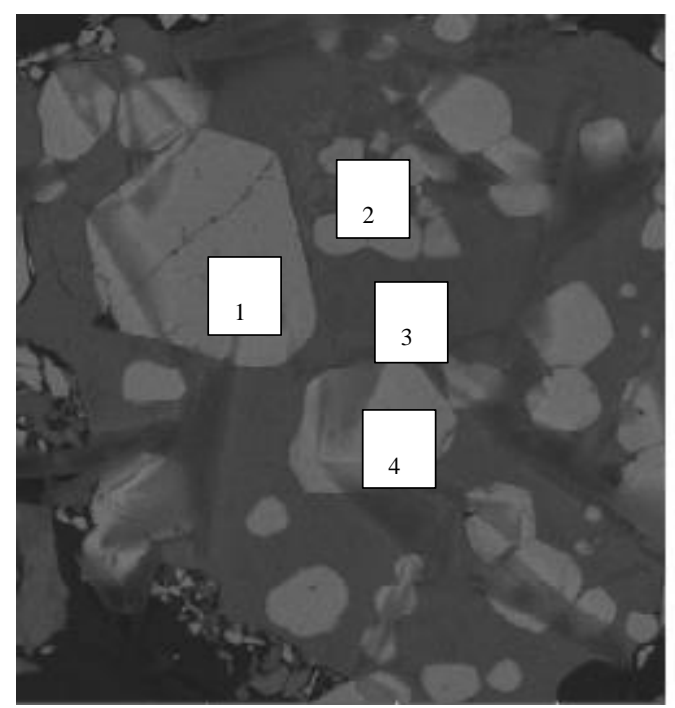

\begin{tabular}{|l|l|l|l|l|l|}
\hline Point & $\mathrm{Mg}$ & $\mathrm{Al}$ & $\mathrm{Si}$ & $\mathrm{Cr}$ & $\mathrm{Fe}$ \\
\hline 1 & 2.09 & 2.91 & 0.00 & 13.23 & 7.62 \\
\hline 2 & 0.42 & 0.00 & 0.59 & 0.00 & 0.18 \\
\hline 3 & 6.30 & 0.34 & 7.55 & 0.22 & 1.70 \\
\hline 4 & 4.31 & 1.19 & 4.35 & 4.97 & 3.53 \\
\hline
\end{tabular}

Figure 4: SEM photomicrograph with microanalysis of different mineral grains 

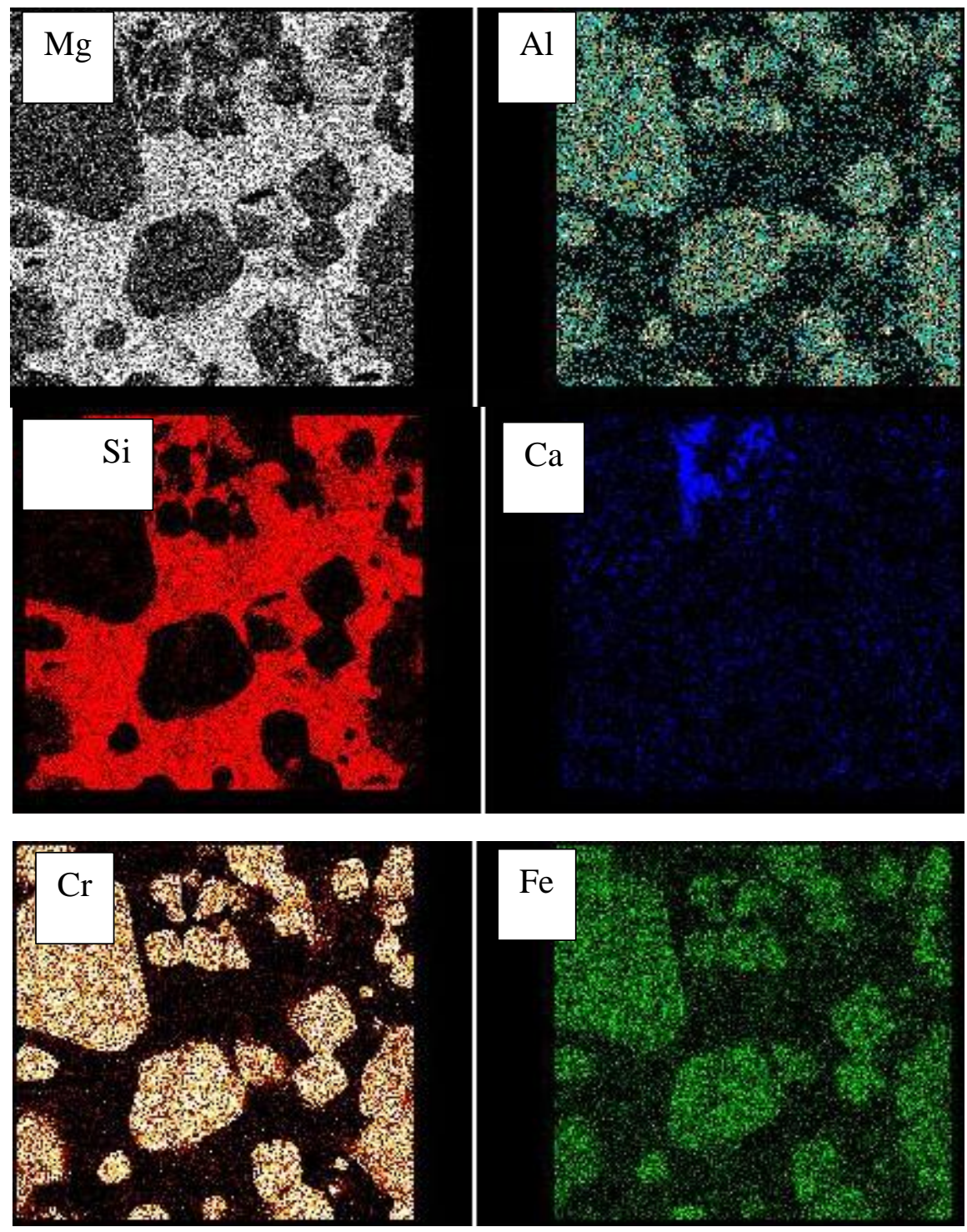

Figure 5: Mapping of various elements (Cr, $\mathrm{Si}, \mathrm{Al}, \mathrm{Fe}, \mathrm{Mg}, \mathrm{Ca})$

SEM Mapping results shown in Figure 5 revealed that the gangue elements $((\mathrm{Cr}, \mathrm{Si}, \mathrm{Al}, \mathrm{Fe}, \mathrm{Mg}, \mathrm{Ca})$ are evenly distributed throughout the sample. Hence finer grinding is required for better liberation of the chormite minerals.

\section{Conclusion}

The characterisation results of the chromite tailings indicated that there is a potential of using South African chromite tailings as a source of chromite if an appropriate method is used in the retreatment of these tailings. Most of the chromite is lost to the tailings in the finer fractions $(<75 \mu \mathrm{m})$ indicating the poor efficiency of gravity concentration methods currently used in industry on finer and ultrafine particles. All though the tailings are fairly coarse, there is need to further mill and liberate the chromite. The chromite is associated with magnesium and as a result, it is expected that separation of chromite by magnetic separation will be easier and will occur at a higher magnetic strength as compared to the ferruginous ores [8]. Further studies need to target recovery of these fine chromite using high intensity magnetic separation. 


\section{Acknowledgements}

The author is thankful for University of Johannesburg support, laboratory facilities, and permission to publish this work.

\section{References}

[1] Michael, L., 2016. Gravity spiral concentrator working principle. 911 Murtallurgit, p. 17.

[2] Murthy, R., Tripathy, S. K. \& Kumar, R., 2011. Chrome ore beneficiation challenges \& opportunities. minerals Engineering, p. 375.

[3] Tripathy, S. K., Banerjee, P. \& Suresh, N., 2015. Magnetic separation studies on ferruginious chromite fine to enhance Cr:Fe ratio. International Journal of Minerals, Metallurgy and Materials Volume 3, p. 217.

[4] Mines, C. o., 2017. Minerals Council of South Africa Facts and Figures 2017. p. 33.

[5] Cicek, T. \& Cocen, I., 2002. Applicability of Mozley multigravity separator (MGS) to fine chromite tailings of Turkish chromite concentrating plants. Minerals Engineering, p. 91.

[6] Abubakre, O., Muriana, R. \& Nwokike, P., 2007. Characterization and beneficiation of Anka chromite ore using magnetic separation process. Journal of minerals and materials characterization and engineering, p. 146.

[7] Lubisi, T. P., Nheta, W., \& Ntuli, F. (2018). Physical, Chemical and Mineralogical Characterization of Fluorspar Flotation Tailings. Materials Today: Proceedings, 5(1), 302-310.

[8] Sunil, T., Rama, M., Veerendra, S. \& Nikkam, S., 2016. Processing of Ferruginous Chromite Ore by Dry High Intensity Magnetic Separation. Mineral Processing and Extractive Metallurgy, p. 196. 